\title{
The Circular Stapled Esophagogastric Anastomosis in Esophagectomy: No Differences in Anastomotic Insufficiency and Stricture Rates Between the $25 \mathrm{~mm}$ and $28 \mathrm{~mm}$ Circular Stapler
}

\author{
E. Tagkalos ${ }^{1}$ (D) P. C. van der Sluis ${ }^{1}$ - E. Uzun ${ }^{1} \cdot$ F. Berlth ${ }^{1} \cdot$ J. Staubitz ${ }^{1} \cdot$ I. Gockel $^{2}$. \\ R. van Hillegersberg ${ }^{3} \cdot$ H. Lang ${ }^{1} \cdot$ Peter P. Grimminger $^{1}$
}

Received: 13 May 2020 / Accepted: 12 December 2020 / Published online: 27 January 2021

(C) 2021 The Author(s)

\begin{abstract}
Background For patients undergoing an Ivor Lewis esophagectomy with a circular stapled anastomosis, the optimal diameter of the used circular stapler to restore continuity is unknown. The aim of this study was to compare the $25 \mathrm{~mm}$ stapled versus the $28 \mathrm{~mm}$ stapled esophagogastric anastomosis after Ivor Lewis esophagectomy, focusing on anastomotic insufficiency and postoperative anastomotic strictures.

Methods Between February 2008 and June 2019, 349 consecutive patients underwent Ivor Lewis esophagectomy with gastric conduit reconstruction and circular stapled anastomosis. Patient characteristics and postoperative results, such as anastomotic insufficiency rates, postoperative anastomotic stricture rates, time to anastomotic stricture rate, and the number of dilatations, were recorded in a prospective database and analyzed.

Results In 222 patients (64\%), the $25 \mathrm{~mm}$ circular stapler was used and in 127 patients (36\%) the $28 \mathrm{~mm}$ circular stapler was used. There were no differences in baseline characteristics. Anastomotic insufficiency rates were comparable between the $25 \mathrm{~mm}$ $(12 \%)$ and the $28 \mathrm{~mm}$ groups $(11 \%)(p=0.751)$. There were no differences between postoperative anastomotic strictures in the $25 \mathrm{~mm}(14 \%)$ and the $28 \mathrm{~mm}$ groups $(14 \%)(p=0.863)$. Within patients with postoperative anastomotic strictures, a median number of 2 dilatations were observed in each group $(p=0.573)$ without differences in the time to first diagnosis $(p=0.412)$.

Conclusion There were no differences in anastomotic insufficiency and postoperative anastomotic stricture rates between the $25 \mathrm{~mm}$ and the $28 \mathrm{~mm}$ circular stapled esophagogastric anastomosis after Ivor Lewis esophagectomy. Both the $25 \mathrm{~mm}$ and $28 \mathrm{~mm}$ stapler can be safely used to create a circular stapled esophagogastric anastomosis to restore continuity after esophagectomy.
\end{abstract}

Keywords Ivor-Lewis Esophagectomy · Circular stapled anastomosis · Esophago-gastric anastomosis

E. Tagkalos and P. C. van der Sluis contributed equally to this work.

Peter P. Grimminger

Peter.grimminger@unimedizin-mainz.de

1 Department of General, Visceral and Transplant Surgery, University Medical Center of the Johannes Gutenberg University Mainz, Mainz, Germany

2 Department of Visceral, Transplant, Thoracic and Vascular Surgery, University Hospital of Leipzig, Leipzig, Germany

3 Department of Surgery, University Medical Center Utrecht, Utrecht, The Netherlands

\section{Background}

Neoadjuvant treatment followed by esophagectomy with 2field lymphadenectomy is the golden standard in the surgical treatment of patients with esophageal cancer. ${ }^{1-3}$ Compared to an open transthoracic esophagectomy (robot assisted), minimally invasive esophagectomy results in a lower percentage of postoperative complications. ${ }^{4,5}$ After esophagectomy, continuity of the gastrointestinal tract is restored by creating a gastric conduit with an esophagogastric anastomosis. However, it is currently unknown, if a McKeown procedure (cervical anastomosis) or an Ivor Lewis procedure (intrathoracic anastomosis) should be preferred for patients with 
esophageal cancer undergoing esophagectomy. ${ }^{6,7}$ In our hospital, the Ivor Lewis procedure is the preferred therapeutic option for patients undergoing esophagectomy, based on the hypothesis that high-intrathoracic anastomosis is to be associated with a lower anastomotic insufficiency rates, lower rates of recurrent laryngeal nerve palsy, and a shorter in-hospital stay, as compared to cervical anastomosis. ${ }^{8}$

Different surgical techniques exist to create the (minimally invasive) intrathoracic esophagogastric anastomosis in the context of Ivor Lewis procedure: hand sewn, linear stapled, and circular stapled. ${ }^{9-12}$ Few studies have suggested superiority of a stapled over a hand-sewn anastomosis considering insufficiency rates. ${ }^{13,14}$ Therefore, the circular stapled esophagogastric anastomosis is the preferred surgical technique to restore upper gastrointestinal continuity in our hospital. ${ }^{12}$

For a circular stapled anastomosis, different stapler diameters are available, and the most frequently used ones have a diameter of $25 \mathrm{~mm}$ and $28 \mathrm{~mm}$. In a recent meta-analysis, different circular stapler diameters used for the esophagogastric anastomosis were compared.$^{13}$ It was shown that the use of a $28 \mathrm{~mm}$ circular stapler was strongly associated with a reduced risk of postoperative anastomotic stricture in the upper GI tract compared to a 25 mm circular stapler. ${ }^{14}$

In this article, we present our experience with the $25 \mathrm{~mm}$ and $28 \mathrm{~mm}$ circular stapler devices for esophagogastric anastomosis after esophagectomy in a large volume tertiary referral center for esophageal cancer. The aim of this study was to compare the incidence of anastomotic insufficiency and anastomotic strictures associated with the two different sizes.

\section{Methods}

Between February 2008 and June 2019, patients with resectable esophageal cancer who underwent Ivor Lewis esophagectomy with a circular stapled anastomosis in the University Medical Center of the Johannes Gutenberg University (Mainz, Germany) were included in the analysis. Data on patient characteristics, surgical procedures, and postoperative outcomes were registered prospectively in an institutional database and were retrospectively analyzed. Postoperative complications were graded according to definitions stated by the modified Clavien-Dindo classification (MCDC) or the Esophagectomy Complications Consensus Group (ECCG). ${ }^{15,16}$ All anastomotic insufficiencies were symptomatic and were assessed by a CT scan with oral contrast and gastroscopy. All postoperative anastomotic strictures were symptomatic and were assessed by gastroscopy.

This study was approved by the medical ethical institutional review board of the Johannes Gutenberg University (JGU) of Mainz and the requirement to obtain informed consent was waived. Our department within the JGU is board certified and follows the guidelines of the German Cancer Society (DKG) for treatment of upper gastrointestinal cancer. Preoperative work-up included esophago-gastroscopy combined with endoscopic ultrasonography (EUS), tumor biopsy, and a combined thoracic and abdominal computed tomography (CT) scan. Positron emission tomography (PET)-CT scans were only used on indication when distant metastases outside the operative field were suspected. After preoperative work-up, patients were discussed in a multidisciplinary tumor board to determine optimal neoadjuvant and surgical treatment according to the current guidelines.

\section{Perioperative Management}

All patients underwent a endoscopic preoperative dilatation of the pylorus on the day before esophagectomy to decrease the rate of delayed gastric emptying after Ivor Lewis esophagectomy. ${ }^{17}$

All patients received an epidural catheter to supply sufficient postoperative analgesia. Patients were intubated with a left-sided double-lumen tube to facilitate desufflation of the right lung. Prior to incision, intravenous antibiotic prophylaxis (sulbactam $1000 \mathrm{mg}$ and ampicillin $2000 \mathrm{mg}$ ) was administered. No nasogastric tubes were placed postoperatively. Postoperatively, all patients were directly extubated in the operating room. Hereafter, patients were transferred to the intensive care unit (ICU) for respiratory and hemodynamic monitoring. On postoperative day 1 , hemodynamically and respiratory stable patients were transferred to the surgical ward for further postoperative recovery. The first 3 days postoperatively, patients were placed on a nil-by-mouth routine. On the 4th day postoperatively, patients started with sips of water in absence of clinical signs of anastomotic insufficiency. Hereafter, oral intake was gradually increased to solid food. Esophageal swallow tests to prove or exclude anastomotic insufficiency were not routinely performed. There was no enhanced recovery or fast track program.

\section{Operating Procedure}

There were 4 different approaches of Ivor Lewis esophagectomy with circular stapled intrathoracic anastomosis performed:

- Open transthoracic esophagectomy (OE)

- Hybrid esophagectomy (HE)

- Minimally invasive esophagectomy (MIE)

- Robot-assisted minimally invasive esophagectomy (RAMIE)

In $\mathrm{OE}$, gastric mobilization and abdominal lymphadenectomy was performed through a laparotomy and esophageal mobilization with intrathoracic lymphadenectomy by a right- 
Table 1 Patient demographics and tumor characteristics $(n=349)$

\begin{tabular}{|c|c|c|c|}
\hline & $25 \mathrm{~mm}$ circular stapler $(n=222)$ & $28 \mathrm{~mm}$ circular stapler $(n=127)$ & $p$ value \\
\hline Age (years) (median) (minimum-maximum) & $63(25-85)$ & $64(30-84)$ & 0.328 \\
\hline \multicolumn{4}{|l|}{ Gender $(n(\%))$} \\
\hline Male & $184(83)$ & $107(85)$ & 0.741 \\
\hline Female & $38(17)$ & $20(16)$ & \\
\hline BMI $\left(\mathrm{kg} / \mathrm{m}^{2}\right)$ (median) (minimum-maximum) & $26(16-51)$ & $25(15-46)$ & 0.210 \\
\hline \multicolumn{4}{|l|}{ Comorbidity $(n(\%))$} \\
\hline No comorbidity & $47(21)$ & $37(29)$ & 0.094 \\
\hline Vascular & $113(51)$ & $61(48)$ & 0.606 \\
\hline Cardiac & $54(24)$ & $24(18,9)$ & 0.242 \\
\hline Diabetes & $28(13)$ & $25(20)$ & 0.077 \\
\hline Pulmonary & $50(23)$ & $20(16)$ & 0.128 \\
\hline Oncologic & $21(10)$ & $10(8)$ & 0.616 \\
\hline Previous abdominal operation & $71(32)$ & $33(26)$ & 0.239 \\
\hline Neurologic & $15(7)$ & $10(8)$ & 0.570 \\
\hline \multicolumn{4}{|l|}{ ASA score $(n(\%))$} \\
\hline 2 & $107(48)$ & $56(44)$ & 0.410 \\
\hline 3 & $111(50)$ & $66(52)$ & \\
\hline 4 & $4(2)$ & $5(4)$ & \\
\hline \multicolumn{3}{|l|}{ Clinical stage groups (TNM 8) (n (\%)) } & 0.313 \\
\hline cTxN0 & $8(4)$ & $1(1)$ & \\
\hline cTxN1 & $13(6)$ & $1(1)$ & \\
\hline cT1aN0 & $8(4)$ & $2(2)$ & \\
\hline cT1aN1 & $3(1)$ & $1(1)$ & \\
\hline cT1aN2 & $1(1)$ & $0(0)$ & \\
\hline cT1bN0 & $10(5)$ & $2(2)$ & \\
\hline cT1bN1 & $2(1)$ & $1(1)$ & \\
\hline cT1bN2 & $1(1)$ & $0(0)$ & \\
\hline cT2N0 & $24(11)$ & $13(10)$ & \\
\hline cT2N1 & $16(7)$ & $6(5)$ & \\
\hline cT2N2 & $2(1)$ & $1(1)$ & \\
\hline cT2N3 & $1(1)$ & $0(0)$ & \\
\hline cT3NO & $23(10)$ & $18(14)$ & \\
\hline cT3N1 & $77(35)$ & $57(45)$ & \\
\hline cT3N2 & $18(8)$ & $11(9)$ & \\
\hline cT3N3 & $3(1)$ & $2(2)$ & \\
\hline cT4aN0 & $4(2)$ & $1(1)$ & \\
\hline cT4aN1 & $6(3)$ & $8(6)$ & \\
\hline $\mathrm{cT} 4 \mathrm{aN} 2$ & $2(1)$ & $2(2)$ & \\
\hline \multicolumn{3}{|l|}{ Tumor location $(n(\%))$} & 0.704 \\
\hline Upper esophageal & $1(1)$ & $0(0)$ & \\
\hline Middle esophageal & $25(11)$ & $16(12)$ & \\
\hline Lower esophageal/GEJ & $196(88)$ & $111(87)$ & \\
\hline \multicolumn{3}{|l|}{ Tumor type (n (\%)) } & 0.217 \\
\hline Adenocarcinoma & $165(74)$ & $97(77)$ & \\
\hline Squamous cell carcinoma & $56(25)$ & $28(22)$ & \\
\hline Melanoma & $1(0)$ & $0(0)$ & \\
\hline Neuro-endocrine & $0(0)$ & $2(2)$ & \\
\hline \multicolumn{3}{|l|}{ Neoadjuvant treatment $(n(\%))$} & 0.154 \\
\hline No therapy & $66(30)$ & $25(20)$ & \\
\hline Chemotherapy & $73(33)$ & $43(34)$ & \\
\hline Chemoradiotherapy & $82(37)$ & $58(46)$ & \\
\hline Radiotherapy & $1(1)$ & $0(0)$ & \\
\hline
\end{tabular}

sided thoracotomy. HE was comparable to $\mathrm{OE}$, but for the abdominal phase, a laparoscopic approach was used. In MIE, laparoscopic gastric mobilization and abdominal lymphadenectomy was followed by a minimally invasive thoracic phase. The RAMIE procedure was similar to MIE with the use of the Da Vinci® Xi robotic system (Intuitive Surgical Inc., Sunnyvale, CA, USA). In all procedures, the circular staple anvil ( $25 \mathrm{~mm}$ or $28 \mathrm{~mm}$ ) was secured by a purse string suture.
The circular stapled anastomosis was routinely oversewn and an omental wrap was placed around the anastomosis. ${ }^{12}$

All patients underwent esophagectomy with en bloc 2-field lymphadenectomy with Ivor Lewis gastric conduit reconstruction using a $25 \mathrm{~mm}$ or a $28 \mathrm{~mm}$ circular stapler (DST Series EEA, Medtronic, USA) for the esophagogastric anastomosis. The size of the circular stapler was chosen by the operating surgeon depending on the diameter of the lumen remaining 
Table 2 Operative details $(n=349)$

$25 \mathrm{~mm}$ circular $28 \mathrm{~mm}$ circular $\quad p$ value

stapler $(n=222) \quad$ stapler $(n=127)$

\begin{tabular}{|c|c|c|c|}
\hline \multicolumn{3}{|l|}{ Operative approach } & \multirow[t]{5}{*}{$p<0.001$} \\
\hline Open & $56(25)$ & $2(2)$ & \\
\hline Hybrid & $81(37)$ & $14(11)$ & \\
\hline MIE & $57(26)$ & $25(20)$ & \\
\hline RAMIE & $28(13)$ & $86(68)$ & \\
\hline \multicolumn{4}{|c|}{ Operating time (min) (mean-SD) } \\
\hline Total operating time & $397 \pm 79$ & $384 \pm 82$ & 0.134 \\
\hline
\end{tabular}

proximal esophagus after transection in order to create an optimal esophagogastric anastomosis.

The esophagectomy resection specimen included a thoracic lymph node dissection with the paratracheal right-sided (lymph node station 2R), tracheobronchial (lymph node station 4), subcarinal (station 7), and peri-esophageal (station 8) lymph nodes. ${ }^{18,19}$ A D1+ abdominal lymphadenectomy was performed, including lymph nodes located at the portal vein, common hepatic artery, celiac trunk, left gastric artery, suprapancreatic, and lesser omental lymph nodes as well as lymph nodes around the splenic artery. ${ }^{18-20}$

\section{Pathological Analysis}

The 8th edition of the Tumor Node Metastasis (TNM) classification stated by the International Union Against Cancer (UICC) was used to evaluate the resection specimen. ${ }^{20}$

The (circumferential) resection margins were examined using the criteria stated by the College of American Pathologists (CAP). ${ }^{21}$

Table 3 Postoperative data $(n=349)$

\section{Statistical Analysis}

Statistical analysis was performed using SPSS version 25.0 (SPSS, Chicago, IL, USA). All continuous data are presented as medians with range (minimum and maximum) or means with standard deviations. Results for categoric variables are presented as numbers with corresponding percentages. To evaluate significance of differences between groups, the Mann-Whitney $U$ test was used for continuous variables and the chi-squared test was used as for categorical variables.

A binary univariate regression analysis was performed to identify risk factors for anastomotic insufficiency and postoperative anastomotic strictures. All outcomes with $p<0.10$ in the univariate analysis and clinically relevant parameters were included in the binary multivariate regression analysis to identify independent risk factors for anastomotic insufficiency and postoperative anastomotic strictures.

\section{Results}

Between February 2008 and June 2019, 349 patients with resectable esophageal cancer underwent Ivor Lewis esophagectomy with a circular stapled anastomosis. In 222 patients (64\%), a $25 \mathrm{~mm}$ circular stapler was used, and in 127 (36\%), a $28 \mathrm{~mm}$ device applied. There were no differences in baseline characteristics between the two groups and baseline characteristics were representative for patients with esophageal cancer in the Western world (Table 1).

In the $25 \mathrm{~mm}$ group, there were significantly more $\mathrm{OE}$ and HE procedures, compared to the $28 \mathrm{~mm}$ group, where the majority of patients underwent RAMIE $(p<0.001)$. There were no differences in total operating time between the $25 \mathrm{~mm}$ and $28 \mathrm{~mm}$ groups (Table 2).

\begin{tabular}{llll}
\hline & $\begin{array}{l}25 \text { mm circular } \\
\text { stapler }(n=222)\end{array}$ & $\begin{array}{l}28 \text { mm circular } \\
\text { stapler }(n=127)\end{array}$ & $p$ value \\
\hline Pulmonary complications $(n(\%))$ & $84(38)$ & $36(28)$ & 0.072 \\
Pneumonia & $60(27)$ & $29(23)$ & 0.387 \\
Cardiac complications $(n(\%))$ & $35(16)$ & $18(14)$ & 0.690 \\
Atrial fibrillation & $32(14)$ & $18(14)$ & 0.951 \\
Anastomotic insufficiency $(n(\%))$ & $27(12)$ & $14(11)$ & 0.751 \\
Anastomotic stricture & $30(14)$ & $18(14)$ & 0.863 \\
Number of dilatations (median) (minimum-maximum) & $2(0-19)$ & $2(0-5)$ & 0.573 \\
Time to stricture (days) (median) (minimum-maximum) & $90(27-938)$ & $78(12-243)$ & 0.412 \\
Chylothorax $(n(\%))$ & $7(3)$ & $3(2)$ & 0.670 \\
Recurrent laryngeal nerve palsy $(n(\%))$ & $4(2)$ & $6(5)$ & 0.115 \\
Wound infection $(n(\%))$ & $26(12)$ & $9(7)$ & 0.166 \\
30-day mortality & $3(1)$ & $4(3)$ & 0.249 \\
90-day mortality & $13(6)$ & $6(5)$ & 0.654 \\
\hline
\end{tabular}


Table 4 Univariate and multivariate analysis of the association between risk factors and anastomotic leakage

\begin{tabular}{lllll}
\hline Characteristic & $\begin{array}{l}\text { Unadjusted HR }(95 \% \mathrm{CI}), \\
\text { univariate }\end{array}$ & $p$ & $\begin{array}{l}\text { Unadjusted HR (95\%CI), } \\
\text { multivariate }\end{array}$ & $p$ \\
\hline Stapler (25 versus & $0.802(0.345-1.862)$ & 0.607 & \\
$\quad 28 \mathrm{~mm})$ & $1.016(0.429-2.405)$ & 0.972 & & \\
No comorbidity & $1.012(0.701-1.460)$ & 0.950 & & 0.008 \\
Operative approach & $2.841(1.273-6.338)$ & 0.011 & $2.762(1.304-5.849)$ & \\
Diabetes & & & & \\
\hline
\end{tabular}

There were no differences in anastomotic insufficiency rates between the $25 \mathrm{~mm}(12 \%)$ and the $28 \mathrm{~mm}$ groups $(11 \%)(p=0.751)$. There were also no differences between postoperative anastomotic strictures in the $25 \mathrm{~mm}$ (14\%) and the $28 \mathrm{~mm}$ groups $(14 \%)(p=0.863)$. Also, the median number of dilatations ( $n=2$ in each group, $p=0.573$ ) and the time to first diagnosis of the stricture were not significantly different between the two groups ( $p=0.412$ ).

Considering further postoperative outcomes including pulmonary complications, cardiac complications, chylothorax, wound infections, and 30- and 90-day mortality, there were no differences between the $25 \mathrm{~mm}$ and $28 \mathrm{~mm}$ groups (Table 3).

A binary univariable and multivariable logistic regression analysis was performed to identify risk factors for anastomotic leakage (Table 4) after esophagectomy. The used stapler size ( 25 or $28 \mathrm{~mm}$ ) was not associated with anastomotic leakage (HR 0.802 (95\%CI, 0.345-1.862), $p=0.607$ ) in univariate analysis. A medical history of diabetes was independently associated with the occurrence of anastomotic leakage in both uni- and multivariate analyses (HR 2.762 (95\% CI 1.3045.849), $p=0.008$ ) (Table 4).

A binary univariable logistic regression analysis was performed to identify risk factors for postoperative anastomotic strictures (Table 5) after esophagectomy. The used stapler size ( 25 or $28 \mathrm{~mm}$ ) was not associated with postoperative anastomotic strictures (HR 1.014 (95\%CI 0.465-2.212, $p=0.972$ ) in univariate analysis. Furthermore, anastomotic insufficiency was also not associated with the occurrence of postoperative anastomotic strictures (HR 0.457 (95\%CI 0.134-1.559, $p=$ 0.211 ) in univariate analysis (Table 5).
A radical resection (R0) was observed in $94 \%$ of patients in the $25 \mathrm{~mm}$ group and in $96 \%$ of patients in the $28 \mathrm{~mm}$ group $(p=0.436)$. There were no differences in postoperative pathological stage and histology between groups (Table 6).

\section{Discussion}

In this study, the $25 \mathrm{~mm}$ circular stapler was compared to the $28 \mathrm{~mm}$ stapler for a circular stapled esophagogastric anastomosis after Ivor Lewis esophagectomy. There were no differences between the 25 and $28 \mathrm{~mm}$ circular stapler considering anastomotic insufficiency, postoperative anastomotic strictures, the number of dilations needed, and the time to the first diagnosis of postoperative anastomotic stricture. These data clearly show that both the $25 \mathrm{~mm}$ and the $28 \mathrm{~mm}$ stapler can be used safely to create the intrathoracic esophagogastric anastomosis to restore continuity after esophagectomy. Furthermore, in this study, the only finding which was independently associated with the occurrence of anastomotic insufficiency was a medical history of diabetes.

Currently, there is only one meta-analysis, which compared different circular stapler diameters $(25 \mathrm{~mm}$ versus $28 \mathrm{~mm}$ ) to create the esophagogastric anastomosis. ${ }^{22}$ In this meta-analysis, 5 observational studies were included. ${ }^{23-28}$ It was concluded that the use of larger circular stapler size $(28 \mathrm{~mm}$ versus $25 \mathrm{~mm}$ ) was strongly associated with a reduced risk of postoperative anastomotic strictures in the upper GI tract. ${ }^{22}$ Results from our study do not support the conclusion of aforementioned meta-analysis, as there were no differences observed in anastomotic insufficiency and postoperative anastomotic strictures between the $25 \mathrm{~mm}$ and the $28 \mathrm{~mm}$ stapled
Table 5 Univariate and multivariate analysis of the association between risk factors and postoperative anastomotic strictures

\begin{tabular}{llll}
\hline Characteristic & Unadjusted HR (95\%CI), univariate & $p$ & $\begin{array}{l}\text { Unadjusted HR } \\
\text { (95\%CI), multivariate }\end{array}$ \\
\hline Stapler (25 versus $28 \mathrm{~mm})$ & $1.014(0.465-2.212)$ & 0.972 & \\
No comorbidity & $1.504(0.680-3.326)$ & 0.313 & \\
Operative approach & $1.063(0.752-1.502)$ & 0.729 & \\
Diabetes & $0.947(0.383-2.339)$ & 0.906 & \\
Anastomotic leakage & $0.457(0.134-1.559)$ & 0.211 & \\
\hline
\end{tabular}


Table 6 Histopathological data $(n=349)$

\begin{tabular}{|c|c|c|c|}
\hline & $\begin{array}{l}25 \mathrm{~mm} \text { circular stapler } \\
(n=222)\end{array}$ & $\begin{array}{l}28 \mathrm{~mm} \text { circular stapler } \\
(n=127)\end{array}$ & $p$ value \\
\hline Histological type $(n(\%))$ & & & 0.360 \\
\hline Adenocarcinoma & $151(68)$ & $88(69)$ & \\
\hline Squamous cell carcinoma & $44(20)$ & $22(17)$ & \\
\hline Melanoma & $1(1)$ & $0(0)$ & \\
\hline Neuro-endocrine & $0(0)$ & $2(2)$ & \\
\hline No viable tumor cells & $26(12)$ & $15(12)$ & \\
\hline $\operatorname{Radicality}(n(\%))$ & & & 0.436 \\
\hline $\mathrm{R} 0$ & $209(94)$ & $122(96)$ & \\
\hline $\mathrm{R} 1$ & $13(6)$ & $5(4)$ & \\
\hline Pathological stage groups (TNM 8) $(n(\%))$ & & & 0.110 \\
\hline pT0N0 & $26(12)$ & $15(12)$ & \\
\hline pT0N1 & $5(2)$ & $2(2)$ & \\
\hline pT0N2 & $2(1)$ & $0(0)$ & \\
\hline pT1aN0 & $18(8)$ & $5(4)$ & \\
\hline pT1aN2 & $2(1)$ & $0(0)$ & \\
\hline pT1bN0 & $31(14)$ & $8(6)$ & \\
\hline pT1bN1 & $7(3)$ & $1(1)$ & \\
\hline pT1bN2 & $3(1)$ & $2(2)$ & \\
\hline pT1bN3 & $0(0)$ & $2(2)$ & \\
\hline pT2N0 & $19(9)$ & $13(10)$ & \\
\hline pT2N1 & $16(7)$ & $5(4)$ & \\
\hline pT2N2 & $7(3)$ & $2(2)$ & \\
\hline pT2N3 & $3(1)$ & $1(1)$ & \\
\hline pT3N0 & $32(14)$ & $22(17)$ & \\
\hline pT3N1 & $13(6)$ & $12(9)$ & \\
\hline pT3N2 & $19(9)$ & $19(15)$ & \\
\hline pT3N3 & $16(7)$ & $15(12)$ & \\
\hline pT4aN0 & $0(0)$ & $1(1)$ & \\
\hline pT4aN1 & $1(1)$ & $0(0)$ & \\
\hline pT4aN2 & $1(1)$ & $0(0)$ & \\
\hline pT4aN3 & $1(1)$ & $2(2)$ & \\
\hline
\end{tabular}

esophagogastric anastomosis. The meta-analysis included 367 patients in the $25 \mathrm{~mm}$ and 460 patients in the $28 \mathrm{~mm}$ group (827 patients in total). ${ }^{22}$ Our study included 349 patients (222 in the $25 \mathrm{~mm}$ group and 127 in the $28 \mathrm{~mm}$ group) and might significantly contribute ( $30 \%$ additional patients) evidence that there is no difference in postoperative outcomes between the two stapler diameters applied for a circular stapled intrathoracic anastomosis.

In our study, both postoperative anastomotic stricture rates after the $25 \mathrm{~mm}(14 \%)$ and the $28 \mathrm{~mm}$ stapled anastomosis $(14 \%)$ were comparable to the rate reported $(28 \mathrm{~mm}, 11 \%)$ in the largest study included in the aforementioned meta-analysis. ${ }^{24}$ This shows that our postoperative anastomotic stricture rates observed in our cohort were comparable to other high volume tertiary referral centers and reflect the incidence of postoperative anastomotic stricture rates in daily practice. ${ }^{22,24}$ The size of the circular stapler (25 $\mathrm{mm}$ or $28 \mathrm{~mm}$ ) as used in this study was chosen based on the size of the esophageal lumen after transection. Without a difference in the incidence of anastomotic insufficiency and postoperative anastomotic dilatations after esophagectomy, the surgeon could choose either the $25 \mathrm{~mm}$ or $28 \mathrm{~mm}$ circular stapler to restore continuity based on the estimation of the esophageal lumen. The question, which is the best surgical strategy to create the "ideal" esophagogastric anastomosis after esophagectomy for distal esophageal cancer or cancer of the gastro-esophageal junction, still remains. Results from a metaanalysis including observational studies comparing an Ivor Lewis esophagectomy to a McKeown esophagectomy showed that an Ivor Lewis esophagectomy was associated with a lower incidence of anastomotic leakage, 90-day mortality, and other 
postoperative morbidity. ${ }^{6}$ However, randomized evidence is yet still lacking. The ICAN randomized controlled trial will provide evidence, whether the McKeown procedure is associated with a higher percentage of postoperative complications compared to the Ivor Lewis procedure. ${ }^{7}$ With regard to the latter, it is still unclear how to perform the best anastomotic technique.

In the $25 \mathrm{~mm}$ group, more than $50 \%$ of patients had either an open or hybrid esophagectomy, both through a right thoracotomy. However, in our minimally invasive group, mainly a right mini-thoracotomy was used with a $28 \mathrm{~mm}$ stapler. This could raise questions about the technical feasibility, quality, and performance of the intrathoracic esophagogastric anastomosis. In one of our previous publications, we showed that restoring continuity through a right mini-thoracotomy did not compromise the quality and performance of the anastomosis. ${ }^{29}$

Limitations of this study include the single-center design and a time bias for the $25 \mathrm{~mm}$ anastomosis, according to the surgeon's preference, not the measured diameter of the esophageal lumen. Furthermore, there were no postoperative quality of life and nutritional questionnaires obtained within this study. Results of these questionnaires might show important postoperative functional results of the $25 \mathrm{~mm}$ and $28 \mathrm{~mm}$ stapled anastomosis technique. However, these-in general-have to be interpreted with caution, as they are based on patients' subjective assessment and, thus, not of major importance with regard to the objectives of our current study.

In this study, there were no differences in anastomotic insufficiency and postoperative anastomotic strictures between a $25 \mathrm{~mm}$ and $28 \mathrm{~mm}$ circular stapled gastro-esophageal anastomosis after Ivor Lewis esophagectomy. Randomized controlled trials are needed in order to answer the question, which is the best technique to perform the "ideal" esophagogastric anastomosis after Ivor Lewis esophagectomy.

Authors' Contributions ET, PCS, and EU analyzed and interpreted the acquired data and were major contributors in writing the manuscript.

ET, PCS, EU, FB, JS, and BB were responsible for the acquisition and interpretation of the data and were involved in drafting the manuscript.

HL, IG, RH, and PPG developed and supervised the study conception and design and interpreted the data. They were involved in revising it critically for important intellectual content.

All authors had a major impact on the development of the manuscript. The final manuscript has been read and approved by all authors.

Funding Open Access funding enabled and organized by Projekt DEAL.

Data Availability The datasets used and analyzed during the current study are anonymously available from the corresponding author on reasonable request.

\section{Compliance with Ethical Standards}

Competing Interests The authors declare that there is no conflict of interest.
Ethics Data acquisition was performed according to a retrospective analysis of a prospectively maintained institutional database. We received a statement from the Medical ethical committee of the medical association of Rhineland-Palatinate (Ethik-Kommission der Landesärztekammer Rheinland-Pfalz), which states, that the requirement to obtain informed consent was waived. This procedure was regulated in RhinelandPalatinate by the provincial hospital law (Landeskrankenhausgesetz) $\S$ 36 and $\S 37$.

Open Access This article is licensed under a Creative Commons Attribution 4.0 International License, which permits use, sharing, adaptation, distribution and reproduction in any medium or format, as long as you give appropriate credit to the original author(s) and the source, provide a link to the Creative Commons licence, and indicate if changes were made. The images or other third party material in this article are included in the article's Creative Commons licence, unless indicated otherwise in a credit line to the material. If material is not included in the article's Creative Commons licence and your intended use is not permitted by statutory regulation or exceeds the permitted use, you will need to obtain permission directly from the copyright holder. To view a copy of this licence, visit http://creativecommons.org/licenses/by/4.0/.

\section{References}

1. Omloo JM, Lagarde SM, Hulscher JB, Reitsma JB, Fockens P, van Dekken H, Ten Kate FJ, Obertop H, Tilanus HW, van Lanschot JJ.. Extended transthoracic resection compared with limited transhiatal resection for adenocarcinoma of the mid/ distal esophagus: five-year survival of a randomized clinical trial. Ann Surg. 2007;246:992-1000;

2. Gebski V, Burmeister B, Smithers BM, Foo K, Zalcberg J, Simes J; Australasian Gastro-Intestinal Trials Group. Survival benefits from neoadjuvant chemoradiotherapy or chemotherapy in oesophageal carcinoma: a meta-analysis. Lancet Oncol. 2007;8(3):226-234.

3. Hulscher JB, van Sandick JW, de Boer AG, Wijnhoven BP, Tijssen JG, Fockens P, Stalmeier PF, ten Kate FJ, van Dekken H, Obertop $\mathrm{H}$, Tilanus HW, van Lanschot JJ. Extended transthoracic resection compared with limited transhiatal resection for adenocarcinoma of the esophagus. N Engl J Med. 2002;347:1662-9.

4. Biere SS, van Berge Henegouwen MI, Maas KW, Bonavina L, Rosman C, Garcia JR, Gisbertz SS, Klinkenbijl JH, Hollmann MW, de Lange ES, Bonjer HJ, van der Peet DL, Cuesta MA. Minimally invasive versus open oesophagectomy for patients with oesophageal cancer: a multicentre, open-label, randomised controlled trial. Lancet. 2012;379:1887-92.

5. van der Sluis PC, van der Horst S, May AM, Schippers C, Brosens LAA, Joore HCA, Kroese CC, Haj Mohammad N, Mook S, Vleggaar FP, Borel Rinkes IHM, Ruurda JP, van Hillegersberg R. Robot-assisted Minimally Invasive Thoracolaparoscopic Esophagectomy Versus Open Transthoracic Esophagectomy for Resectable Esophageal Cancer: A Randomized Controlled Trial. Ann Surg. 2019;269:621-630

6. van Workum F, Slaman AE, van Berge Henegouwen MI, Gisbertz SS, Kouwenhoven EA, van Det MJ, van den Wildenberg FJH, Polat F, Luyer MDP, Nieuwenhuijzen GAP, Rosman C. Propensity Score-Matched Analysis Comparing Minimally Invasive Ivor Lewis Versus Minimally Invasive Mckeown Esophagectomy. Ann Surg. 2018 Epub ahead of print

7. van Workum F, Bouwense SA, Luyer MD, Nieuwenhuijzen GA, van der Peet DL, Daams F, Kouwenhoven EA, van Det MJ, van den Wildenberg FJ, Polat F, Gisbertz SS, Henegouwen MI, Heisterkamp J, Langenhoff BS, Martijnse IS, Grutters JP, Klarenbeek BR, Rovers MM, Rosman C. Intrathoracic versus 
Cervical ANastomosis after minimally invasive esophagectomy for esophageal cancer: study protocol of the ICAN randomized controlled trial. Trials. 2016;17:505

8. Gooszen JAH, Goense L, Gisbertz SS, Ruurda JP, van Hillegersberg R, van Berge Henegouwen MI. Intrathoracic versus cervical anastomosis and predictors of anastomotic leakage after oesophagectomy for cancer.Br J Surg. 201;105:552-560

9. Trugeda S, Fernandez-Diaz M J, Rodriguez-Sanjuan J C, Palazuelos C M, Fernandez-Escalante C, Gomez-Fleitas M. Initial results of robot-assisted Ivor-Lewis oesophagectomy with intrathoracic hand-sewn anastomosis in the prone position. Int J Med Robotics Comput Assist Surg 2014; 10: 397-403.

10. Kukar M, Ben-David K, Peng JS, Attwood K, Thomas RM, Hennon M, Nwogu C, Hochwald SN. Minimally Invasive Ivor Lewis Esophagectomy with Linear Stapled Anastomosis Associated with Low Leak and Stricture Rates. J Gastrointest Surg. 2019 Epub ahead of print

11. Wee JO, Bravo-Iniguez CE, Jaklitsch MT. Early experience of robot-assisted esophagectomy with circular end-to-end stapled anastomosis. Ann Thorac Surg 2016; 102: 253-9.

12. Grimminger PP, Hadzijusufovic E, Lang H. Robotic-Assisted Ivor Lewis Esophagectomy (RAMIE) with a Standardized Intrathoracic Circular End-to-side Stapled Anastomosis and a Team of Two (Surgeon and Assistant Only). Thorac Cardiovasc Surg. 2018;66):404-406

13. Liu QX, Qiu Y, Deng XF, Min JX, Dai JG. Comparison of outcomes following end-to-end hand-sewn and mechanical oesophagogastric anastomosis after oesophagectomy for carcinoma: a prospective randomized controlled trial. Eur J Cardiothorac Surg. 2015;47:118-23

14. Harustiak T, Pazdro A, Snajdauf M, Stolz A, Lischke R. Anastomotic leak and stricture after hand-sewn versus linearstapled intrathoracic oesophagogastric anastomosis: single-centre analysis of 415 oesophagectomies. Eur J Cardiothorac Surg. 2016;49:1650-9

15. Dindo D, Demartines N, Clavien PA. Classification of surgical complications: a new proposal with evaluation in a cohort of 6336 patients and results of a survey. Ann Surg. 2004;24:205-13.

16. Low DE, Alderson D, Cecconello I, Chang AC, Darling GE, D'Journo XB, Griffin SM, Hölscher AH, Hofstetter WL, Jobe BA, Kitagawa Y, Kucharczuk JC, Law SY, Lerut TE, Maynard N, Pera M, Peters JH, Pramesh CS, Reynolds JV, Smithers BM, van Lanschot JJ. International Consensus on Standardization of Data Collection for Complications Associated With Esophagectomy: Esophagectomy Complications Consensus Group (ECCG). Ann Surg. 2015;262:286-94

17. Hadzijusufovic E, Tagkalos E, Neumann H, Babic B, Heinrich S, Lang H, Grimminger PP. Preoperative endoscopic pyloric balloon dilatation decreases the rate of delayed gastric emptying after IvorLewis esophagectomy. Dis Esophagus. 2019;32(6):doy0
18. Naruke T, Tsuchiya R, Kondo H, Nakayama H, Asamura H. Lymph node sampling in lung cancer: how should it be done? Eur J Cardiothorac Surg. 1999;16 Suppl 1:S17-24

19. Rizk NP, Ishwaran H, Rice TW, Chen LQ, Schipper PH, Kesler KA, Law S, Lerut TE, Reed CE, Salo JA, Scott WJ, Hofstetter WL, Watson TJ, Allen MS, Rusch VW, Blackstone EH.. Optimum lymphadenectomy for esophageal cancer. Ann Surg 2010;251:46-50

20. D'Journo XB. Clinical implication of the innovations of the 8th edition of the TNM classification for esophageal and esophagogastric cancer. J Thorac Dis. 2018;10:2671-2681

21. Verhage RJ, Zandvoort HJ, ten Kate FJ, van Hillegersberg R. How to define a positive circumferential resection margin in T3 adenocarcinoma of the esophagus. Am J Surg Pathol. 2011;35:919-26

22. Allen W, Wells CI, Greenslade M, Bissett IP, O'Grady G. Association Between Circular Stapler Diameter and Stricture Rates Following Gastrointestinal Anastomosis: Systematic Review and Meta-analysis. World J Surg. 2018;42:3097-3105

23. Cakabay B, Aksel B, Unal E, Bayar S, Kocaoglu H, Demirci S. Influence of the stapler size used in esophagojejunostomy anastomosis: anastomotic leak and strictures after total gastrectomy. Turkiye Klinikleri J Med Sci 2012;32:428-431

24. Deldycke A, Van Daele E, Ceelen W, Van Nieuwenhove Y, Pattyn P. Functional outcome after Ivor Lewis esophagectomy for cancer. J Surg Oncol. 2016;113:24-8

25. Dresner SM, Lamb PJ, Wayman J, Hayes N, Griffin SM. Benign anastomotic stricture following transthoracic subtotal oesophagectomy and stapled oesophago-gastrostomy: risk factors and management. $\mathrm{Br}$ J Surg 2000;87:362-373

26. Johansson J, Zilling T, von Holstein CS, Johnsson F, Oberg S, Walther B. Anastomotic diameters and strictures following esophagectomy and total gastrectomy in 256 patients. World J Surg 2000;24:78-84

27. Petrin G, Ruol A, Battaglia G, Buin F, Merigliano S, Constantini M, Pavei P, Cagol M, Scappin S, Ancona E. Anastomotic stenoses occurring after circular stapling in esophageal cancer surgery. Surg Endoscopÿ 2000 14:670-674

28. Yendamuri S, Gutierrez L, Oni A, Mashtare T, Khushalani N, Yang G, Nava H, Demmy T, Nwogu C. Does circular stapled esophagogastric anastomotic size affect the incidence of postoperative strictures? J Surg Res 2011;165:1-4

29. van der Sluis PC, Tagkalos E, Hadzijusufovic E, Babic B, Uzun E, van Hillegersberg R, Lang H, Grimminger PP. Robot-Assisted Minimally Invasive Esophagectomy with Intrathoracic Anastomosis (Ivor Lewis): Promising Results in 100 Consecutive Patients (the European Experience). J Gastrointest Surg. 2020. Online ahead of print.

Publisher's Note Springer Nature remains neutral with regard to jurisdictional claims in published maps and institutional affiliations. 